\title{
Factors Affecting Organizational Design: A Study on the Selected Dimensions in the Bangladeshi Context
}

\author{
Sahadat Hossain \\ University of Liberal Arts Bangladesh \\ Muhammad Hasibul Hasan \\ University of Liberal Arts Bangladesh \\ Fariha Saleh \\ University of Liberal Arts Bangladesh
}

This paper explores variations in organization design due to factors like industry type, organization size, maturity, technology intensity and strategic focus. Data was collected through a questionnaire survey and Key Informant Interviews (KII). No single factor was found to have a significant impact on all dimensions. Bigger organizations were found to have relatively decentralized information management system and service organizations had decentralized control mechanism and two-way communication practices. Organizations with relatively greater technology focus tended to use decentralized decision making, control mechanism and information management practices.

\section{INTRODUCTION}

Organization Design refers to the set of actions intended to integrate people, facts and technology concerned with a business. Organization Design is considered a vital factor to determine the managerial hierarchy, which acts as foundation to the operation of the organization. Donaldson and Joffe (2014) argue that organizational design should be aligned with situational factors such as organization size, competitive strategy, and task uncertainty, to produce higher organizational performance and group performance (Pearce and David, 1983), while Helfat and Karim (2014) conclude that efficacy of any organizational design or re-design depends on the day to day system of operations. Akatwijuka (2015) reveals technology as a factor of producing certain design efficacy whereas, based on a study of a cross sectional firms, Hernaus, Aleksic and Klindzic (2013) find organizational design to be a source of competitive advantage only if, process and structural characteristics are common. Besides building a strong company culture, the design choices help to create a platform for success that ultimately enhances a firm's capacity to respond to increasing demand and adapt to the continually changing landscape. Guerre et al. (2012) focus on the role of organizational design optimization and innovation to boost performance. Recent research, conducted by Espinosa and Lindah (2015) has revealed that mechanistic organization structure enables better learning environment, which contradicts the finding of the research conducted by Tushman et al. (2015) that ambidextrous designs rather than cross-functional, functional 
and spinout designs is significantly associated with increased innovation outcome. Research in Organization Design, particularly in the context of developing countries is scarce. Some studies were done in the public sector focusing the hierarchical dimensions of the government organs (Jahan, 2006; Ahmed, 2002; Haque, 2001, 1995). But, this research is essentially focusing on the design choices which Bate (2000) differentiates from structure of the organization as a framework through which individuals communicate, claim, lead and control in day to day business operations. As a social system, a business organization must interact constantly with external entities, which makes the situation more complex. Khandwalla (2002) mentions in such organizational complexity, for any sizeable organization anywhere, designing and managing effectively is considered a daunting task, which Bhattacharjee (2013) argues as relatively difficult for third world countries for many reasons. Additionally, individual parameters result in design challenges for the organization (Albers, Wohlgezogen \& Zajac, 2013). Such literature findings clearly outline the necessity of conducting a research regarding design factors specific to third world countries. Moreover, design components should be aligned internally with strategic objectives, reward systems and reporting relationships etc. and externally those should be matched with environmental attributes (Meyer, 2013; Ben-Ner, Kong and Lluis, 2012). So, we need to study whether the different organization design components are consistent (Ben-Ner, Kong and Lluis, 2012), to direct the actions of the firm toward achieving its purpose.

In developing countries, the corporate sector is growing at a steady rate. Both the manufacturing and service industry have been contributing to such development. Some of the organizations are gradually moving toward global periphery which necessitates global strategies. Effectiveness of such global strategies can also be brought through choosing and implementing the right organization design (Larsen, Manning \& Pedersen, 2013). During this development process, it is observed that the organizations have adapted various operational as well as administrative structures such as tall structure, flat structure, flexible design, contingent structure etc. Between traditional and modern approaches, the effectiveness essentially depends on the ownership and commitment (Tolchinsky \& Wenzl, 2014). However, we lack substantial evidence to determine the factors influencing this choice of specific organization model (organic or mechanistic). Most discussions or investigations are based mainly on western society and therefore, may not necessarily be true for the cultures of underdeveloped or developing countries. Therefore, there is a need to investigate the factors of organization design choice in the context developing countries.

\section{REVIEW OF LITERATURE}

Design is as an integral part of organizational change and organization development. Often, business design is conducted in a vacuum, giving attention to the design, which transfers employees from one system to a different one. When accomplished methodically, business design can result in a powerful competitive advantage, together with other efficiencies, through effectively deploying relevant talent to produce results. Although this involves a definite understanding of the organization approach, most use techniques and a well-crafted approach and course of action for making certain long-term accomplishments (Hill, 1996).

A well-designed organization is critical to produce distinct interfaces to make right decisions. Unaligned organizations may struggle to be competent, which is a hindrance toward performance. The growth of frameworks, models and process of organizational design, will make the firms much more viable to compete. An integral premise of all managing ideas is usually that efficiency can arise from organizational design (William, 2007).

According to Meyer (2013) Organizational Layout should line up factors collectively that should be encoded inside hierarchical structural configurations, backed by means of organizational exercises and the layout must render equilibrium constructions of processes to ensure certain handle, generate balance, and soak up doubt. Moreover, creative designers should include attributes into the corporation which give it time to monetize environmental chances. According to Randolph (1981), seven dimensions are related to the organization design, and by interacting with one another, these factors constitute effectiveness as 
whole. The first dimension, the typical layout type, is usually labeled as either mechanistic or organic. The design can be extremely structured, inflexible, detailed (mechanistic) or it may be freely structured, variable, as well as flexible (organic).

Courtright (1989) reviewed mechanic and organic organization system from conflict perspective which was previously examined by Burns \& Stalker (1961) and Weick (1987), with the findings that mechanistic system generates higher authority, command type of communication and structural control. Second and third dimensions are the desired coordination for overall unit task, and the specialization level or desired division of labor to complete the task, which specifies the dimensions of integration and differentiation by Thompson and Galbraith $(1967,1973)$ implemented through coordination by plan, categorization, rules, machine, hierarchy, lateral relation, vertical system and self-contained tasks. Discretion is the fourth dimension, which refers to employees' freedom of choice regarding how they will complete their tasks. Here, discretion can be defined as the degree to which individuals have controls over their unit goals and basic strategies. The fifth dimension, subsequently, is decision making. It truly is often centralized, under the control of the unit's commanders, or even decentralized, with authority devolved to employee. Zábojník (2002) stresses on the decentralized decision making as prevalent where quick response to environment and technology are required, which has been supported closely by Aoki (1986), Athey et al. (1994), and Aghion and Tirole (1997) sequentially. Moreover, Athey et al. (1994) conclude that decentralized decision making does not have an advantageous effect on coordination. The sixth dimension is communications, that can be defined as frequency, directionality, and media which may be verbal or written, and the span may be vertical or horizontal. Skills have been referred as the seventh dimension, which includes content and technical skills that may be created through advanced education to the related field, process and interpersonal skills necessary for leadership, communication and group decision-making. Cummings (2009) reveals five dimensions of organizational design which will vary in terms of behavior depending on whether the organizational type is mechanistic or organic. The five dimensions include organization strategy, which refers to overall approach of business toward market, the structure through which the actions will flow, human resource practices which range from recruitment to employee reward, performance management and management information system of the organization. Iqbal \& Sharma (2012) stress that the form of organization structure depends on the type of strategy adopted, based on which plenty of research has been conducted. They suggest that some corporations usually restrict independence of the employees, while others are usually highly flexible. Structure is essentially a new check in with the ideal selection that a corporation tends to make. This externally focused notion has also been supported by (Miles et al., 1978), meaning the internal interdependencies must be aligned to the outside environmental requirements to achieve organizational objectives effectively. Additionally, Trentin (2012) argues that design strategies in the organization must ensure enterprise-wide information use, environmental management, task self-containment and help create lateral relations that complement the customization capacity of organization, which supports previous research conducted by Liu (2006) in socio-technical system theory.

\section{PROBLEM AND PURPOSE}

This research endeavors to reveal the rationale of organizational design choice for entrepreneurs/managers, particularly in the context of Bangladesh. Additionally, based on the survey outcomes, the research will also highlight the factors of organizational design to evaluate within environment and cultural context of Bangladesh.

The overall approach of mechanistic or organic design depends heavily on the factors related to organization, its environment and culture. Besides, design components refer to the span of management, leadership \& communication style and HR practices etc. Academic literature extensively highlights and discusses the effects of various factors on the organization design choices. However, most of the discussions are generic and do not necessarily capture the national and cultural influences. The general basis of the research is to investigate the factors that influence the choice of organizational design. The general existing hypotheses for this research will include (1) organization size (2) Strategy (3) technology 
(4) maturity, and (5) culture (social). The cultural dimension will subsequently be broken down according to its various elements. Previously, organizational culture has been studied as a factor of organizational structure (Janićijević, 2013). On the contrary, Tran and Tian (2013) argue that factors like size, technology and environment etc. render the firms to choose certain structure over others by creating some economic and other constraints. As organizations must go through multiple environment facets, the designer must avoid rigid configurations through denying the tight consistence between organizational and environmental elements (Meyer, 2013). These factors encompass both internal and external dimensions to the organization. By analyzing these combined factors which create a complex business situation, this study will help to understand the rationale of choosing particular design model.

\section{METHODOLOGY}

To address the objectives this research, both qualitative and quantitative approaches have been used. This research is essentially investigating the different design models preferred by the entrepreneurs/managers. Besides, this will reveal the factors influencing behind those preferred models. To address these objectives, primary data has been collected from the target respondents through structured questionnaire and key informant interviews. The structured questionnaire was designed based on the various components of organization design like span of management, leadership and communication mechanisms and controlling system etc. to determine the type of design model followed by the selected organizations. The questionnaire includes questions related to strategy of the organization, extent of technology use, related operating environment, years of operations in the industry and culture along with some demographic questions. Both the components and influencing factors were validated through reviewing relevant literature. These factors have been analyzed to investigate the variation in organization design choices. The structured Key Informant Interviews (KII) were conducted to the focal persons working at strategic level of the organizations. The KII helped to cross validate the collected data through questionnaire and brought out some qualitative design issues concerning the organization.

Data has been collected through the survey questionnaire from a sample of 200 respondents covering 163 firms that belong to different industries in both manufacturing and service industries. Finally, 163 respondents were taken in to consideration, comprising a single respondent from each organization. The sample covered a mixture in terms of organization size, type of industry and origin etc. A variety of demographic factors like gender, age, length of service, position was also considered in selecting the respondents from respective organizations.

The target respondents were reached through a combination of both random and snowball sampling mechanisms. A total 360 final year BBA students of University of Liberal Arts Bangladesh were communicated through 6 business school teachers. Each of the students was instructed to search out an organization where people within their own network are working. Some industries were intentionally excluded for collecting data like; Education and Banking to avoid the biasness and unnecessary convenience which often lead to compromise of the quality of data. Students were also instructed to keep their search limited within the scope of mid to strategic level employees working with such organizations. The students communicated to those respective employees within their network to inform the survey issue and feedback on the participation interest to the survey. Each student gave feedback to the respective teachers regarding the feedback of prospective respondents and their interest to participate in the survey. Teachers scrutinized the types of industry where the prospective participants working with, their positions etc. Based on the contact collected by the students, 200 prospective participants were sent the survey instrument through e-mail. In some cases, the participants were requested to provide their own contacts to participate in the survey. A set of ten well trained data collectors were consulted properly on the contents of the instruments. It took four months to collect the survey data, while simultaneously the researchers conducted the KII to the surveyed organizations, based on participation of four strategic level executives and four mid-level managers. The KIIs were conducted with the employees of four firms belong to four

different industries. The survey was operated on 1 to 2 employees of each organization who are working preferably in mid to high level positions. The collected data was properly filtered through proper 
screening. The collected data was analyzed through using Statistical Package for Social Sciences (SPSS). To understand significance of the variations in the analysis a Mann Whitney-U test was conducted which is considered as appropriate to see the difference between two groups (Hossain \& Hasan, 2016). The outcomes of analysis essentially led the researchers to recommend certain design issues suitable for the organizations.

\section{ANALYSIS AND FINDINGS}

Based on the sample data from 163 respondents, Mean and Standard Deviation have been calculated which further analyzed through Mann-Whitney $U$ to find the differences in overall design parameter as well as its five selected dimensions.

The following table analyzes the overall design and its selected dimensions based on the data collected from manufacturing and service industries.

TABLE 1

INDUSTRY TYPE AND ORGANIZATIONAL DESIGN DIMENSIONS

\begin{tabular}{|l|r|c|c|c|c|c|r|r|r|}
\hline \multirow{4}{*}{} & \multicolumn{9}{|c|}{ Industry Type } \\
\cline { 2 - 11 } & \multicolumn{3}{|c|}{ Manufacturing } & \multicolumn{3}{c|}{ Service } & \multicolumn{3}{c|}{ Mann-Whitney U } \\
\cline { 2 - 11 } & $\mathrm{N}$ & $\mathrm{M}$ & \multicolumn{1}{|c|}{ SD } & $\mathrm{N}$ & $\mathrm{M}$ & \multicolumn{1}{c|}{ SD } & M-WU & \multicolumn{1}{c|}{ Z } & \multicolumn{1}{c|}{ Sig } \\
\hline Organizational Design & 61 & 3.5661 & .39796 & 102 & 3.6398 & .42153 & 2835.000 & -.948 & .294 \\
\hline Organizational Structure & 61 & 3.4918 & .90135 & 102 & 3.5392 & .87225 & 3011.5 & -.346 & .365 \\
\hline Span of Control & 61 & 3.4180 & .59112 & 102 & 3.9515 & .56980 & 2626.0 & -1.977 & .047 \\
\hline Decision Making & 61 & 3.8074 & .52717 & 102 & 3.7034 & .67554 & 2857.5 & -.879 & .369 \\
\hline Information Management & 61 & 3.9918 & .77724 & 102 & 4.1176 & .74852 & 2836.5 & -.966 & .327 \\
\hline Communication Style & 61 & 3.3689 & .74667 & 102 & 4.1882 & .77527 & 2565.5 & -1.998 & .043 \\
\hline
\end{tabular}

The above table indicates that industry type doesn't stand as significant differentiator of overall organizational design. Although, to the dimensions like organization structure and information management, based on the sample statistics, mean scores appear higher in service organizations than those of manufacturing firms, and decision making is higher in manufacturing than those of service organizations, but such differences don't stand significant in population parameter as their resulted values are more than the significance value ( 0.05 at two tailed).

On the contrary, span of control and communication style are found to be higher in service sector which are statistically significant $(0.047<0.05$ and $0.043<0.05$ respectively at 2 tailed). It seems from the KII that in service industries, span of control is more decentralized and communication is more two-way in nature due to its necessity rather than the discretion of the top management. As employees engaged in clientele services can't wait long for instant decisions otherwise, that may create dissatisfaction to the clients which is an issue of top priority for top management.

Apart from that, service organizations provide in most of the cases based on our sample data, technical services for which management must communicate lower order employees involved in clientele services, which necessitates two-way communications at an enhanced level than those of manufacturing organizations. 
TABLE 2

ORGANIZATION SIZE AND ORGANIZATIONAL DESIGN DIMENSIONS

\begin{tabular}{|l|c|c|c|c|c|c|c|c|r|}
\hline \multirow{2}{*}{} & \multicolumn{9}{|c|}{ Size of Organization } \\
\cline { 2 - 11 } & \multicolumn{3}{|c|}{ Small-Medium } & \multicolumn{3}{c|}{ Medium-Large } & \multicolumn{3}{c|}{ Mann-Whitney U } \\
\cline { 2 - 11 } & $\mathrm{N}$ & $\mathrm{M}$ & $\mathrm{SD}$ & $\mathrm{N}$ & $\mathrm{M}$ & $\mathrm{SD}$ & $\mathrm{M}-\mathrm{WU}$ & $\mathrm{Z}$ & Sig \\
\hline Organizational Design & 81 & 3.5973 & .45579 & 83 & 3.6270 & .36853 & 3135.5 & -.617 & .469 \\
\hline Organizational Structure & 81 & 3.5617 & .85653 & 83 & 3.4817 & .90760 & 3164.0 & -.529 & .499 \\
\hline Span of Control & 81 & 3.4877 & .62363 & 83 & 3.5152 & .53626 & 3307.0 & -.047 & .481 \\
\hline Decision Making & 81 & 3.7130 & .66393 & 83 & 3.7713 & .58558 & 3147.5 & -.582 & .280 \\
\hline Information Management & 81 & 3.2470 & .78621 & 83 & 4.1159 & .73409 & 3072.5 & -.847 & .048 \\
\hline Communication Style & 81 & 3.4568 & .82613 & 83 & 3.5549 & .71148 & 3147.5 & -.588 & .479 \\
\hline
\end{tabular}

The above table analyzes dimensions of organizational design and the overall design based on the size of the organization. The total one hundred and sixty-three organizations have been categorized in small to medium and medium to large ranges. Here, Size of the organization mostly, doesn't reflect any variations to the dimensions, as we see the mean scores of overall design and all dimensions except information management are closer for both size ranges. The only variation appears to the information management dimension with a higher mean value to the medium to large organizations, which is statistically significant $(0.048<0.05$ at two tailed $)$.

Such findings clearly depict that relatively larger organizations tend to decentralize their information management system. Furthermore, the KIIs revealed that the size of the organizations is not a major differentiator unless major factors like technology, maturity and strategic focus haven't been adapted to the overall design philosophy. The owner and top management by default, due to the heritage and power orientation in a traditional social structure, are not inclined to leave the authority to the lower levels. But in case of size of the organizations, a large volume of information is difficult to manage centrally and often linger the decision-making process at various levels of the organizations which means top management must delegate the information management to the lower levels. Here, it's worth pointing out that, size of the organization was defined in terms of the number of employees rather than yearly revenue. In retrospect, this seems to be a deficiency.

Although number of employees was considered from the design perspective and Human Relation view, a combination with revenue volume might have given us better picture to categorize and variations in design of the researched organizations.

TABLE 3

MATURITY OF ORGANIZATION AND ORGANIZATIONAL DESIGN DIMENSIONS

\begin{tabular}{|l|c|c|c|c|c|c|c|c|c|}
\hline \multirow{3}{*}{} & \multicolumn{9}{|c|}{ Maturity of the Organization } \\
\cline { 2 - 11 } & \multicolumn{3}{|c|}{10 years of less } & \multicolumn{2}{c|}{ More than 10 years } & \multicolumn{3}{c|}{ Mann-Whitney U } \\
\cline { 2 - 11 } & $\mathrm{N}$ & $\mathrm{M}$ & $\mathrm{SD}$ & $\mathrm{N}$ & $\mathrm{M}$ & $\mathrm{SD}$ & $\mathrm{M}-$ WU & Z & Sig \\
\hline Organizational Design & 46 & 3.9059 & .39517 & 117 & 3.5754 & .41592 & 2255.000 & -2.130 & .047 \\
\hline Organizational Structure & 46 & 3.6196 & .80405 & 117 & 3.4829 & .90956 & 2446.000 & -.917 & .179 \\
\hline Span of Control & 46 & 3.5707 & .60705 & 117 & 3.4744 & .56894 & 2393.500 & -1.106 & .041 \\
\hline Decision Making & 46 & 3.9022 & .45178 & 117 & 3.6795 & .67182 & 2176.000 & -2.120 & .032 \\
\hline Information Management & 46 & 4.1196 & .71635 & 117 & 4.0513 & .77789 & 2544.000 & -.556 & .281 \\
\hline Communication Style & 46 & 3.4239 & .76715 & 117 & 3.5385 & .77168 & 2447.000 & -.919 & .165 \\
\hline
\end{tabular}


Based on the year of operations of the organizations in the industry, overall design of the organizations varies significantly $(0.047<0.05$ at 2 tailed). Among the dimensions of organizational design, span of control and decision making significantly differs based on the maturity of the organization. Here, for decision making calculated $Z$ value was found $-2.12<-1.96$ (at 0.05 at two tailed). Based on the maturity, span of control of the organization also significantly differs (as $0.041<0.05$ at two tailed). Although the mean scores of organization structure and information management appear to be higher to the less aged organizations and mean score of communication style appear to be higher to the more aged organizations, such differences were not found statistically significant. Although, more matured organizations should have relatively horizontal hierarchical structure, decentralized decision making, information management and control mechanisms interestingly, except communication style other for dimensions of design choice along with the overall design produced higher mean score for the less matured organizations. The subsequent KII demystified such conundrum. The participants replied that as the organization is getting matured, it also flourishes in terms of size. Such expansion of the organization creates a distance between top management and functional level management which ultimately translated in more rules and regulations, greater control, a centrality mindset in decision making that leads to a vertical hierarchical structure to create more accountability, checks and balances for the functional level employees' endeavors and performances. Regarding the communication style, the participant mentioned that top management with the parallel to formal rigid communication mechanism within a vertical structure, also creates an informal two-way communication in multi-levels of the organization.

There are two purposes of such style: firstly, to ensure a keen eye over the functional level to have greater control and offsetting the distance between two tiers of management through an informal channel where functional or lower level employees will always remain in a prejudice of empowered feelings.

TABLE 4

TECHNOLOGY INTENSITY AND ORGANIZATIONAL DESIGN DIMENSIONS

\begin{tabular}{|l|r|c|c|c|c|c|c|r|r|}
\hline \multirow{3}{*}{} & \multicolumn{9}{|c|}{ Technology Intensity } \\
\cline { 2 - 11 } & \multicolumn{2}{|c|}{ Low use $(<70 \%)$} & \multicolumn{2}{c|}{ High use $(>70 \%)$} & \multicolumn{3}{c|}{ Mann-Whitney U } \\
\cline { 2 - 11 } & $\mathrm{N}$ & $\mathrm{M}$ & \multicolumn{1}{c|}{ SD } & $\mathrm{N}$ & $\mathrm{M}$ & \multicolumn{1}{c|}{ SD } & M-WU & \multicolumn{1}{c|}{ Z } & \multicolumn{1}{c|}{ Sig } \\
\hline Organizational Design & 71 & 3.6239 & .39599 & 92 & 3.6032 & .42791 & 3137.000 & -.432 & .332 \\
\hline Organizational Structure & 71 & 3.5845 & .79276 & 92 & 3.4728 & .94452 & 3029.500 & -.804 & .421 \\
\hline Span of Control & 71 & 3.5599 & .63452 & 92 & 4.1565 & .53273 & 2923.000 & -2.158 & .048 \\
\hline Decision Making & 71 & 3.1028 & .58541 & 92 & 4.0957 & .65237 & 2931.500 & -2.112 & .041 \\
\hline Information Management & 71 & 3.9085 & .82076 & 92 & 4.1957 & .68723 & 2620.500 & -2.218 & .013 \\
\hline Communication Style & 71 & 3.5141 & .82796 & 92 & 3.5000 & .72627 & 3098.500 & -.572 & .483 \\
\hline
\end{tabular}

Although, technology has brought revolutionary changes in the business domain still, such changes are yet to influence the overall organization design in Bangladesh. From the analysis of collected data, it is apparent that technology has immense impact in the areas of organization design, such as information management, span of control and decision making. Based on the extent of technology use, heavy user organizations were found to significantly differ in terms of information management $(0.013<0.05$ at two tailed) organizations who are light users. Again, both the decision making and span of control respectively were also found to vary significantly $(0.041<0.05$ and $0.048<0.05$ respectively at two tailed) based on use of technology by the organizations. The structure and communication style dimensions of the organization design don't have any statistically significant differences between the high using and low using organizations. As technology is considered a technical area, top management leaves the decisionmaking authority to employees with technical expertise, which automatically necessitates higher control on the self-work domain. Regarding the information management, a common response from the KII 
participants were that they can access all information they require, and hence they responded positively. Still, they also mentioned that the strategic level information were neither required for their work nor do they have any interest to know what planning goes on at top level unless such planning information, are directly impacting their work domain and organizational status.

Apart from all those, the apparent part is organization structure and overall design remain same irrespective of the use of technology. This clearly implies the top management's rigid notion of translating technological dimension to the hierarchical structure and overall design choices of the organization.

TABLE 5

STRATEGIC FOCUS AND ORGANIZATIONAL DESIGN DIMENSIONS

\begin{tabular}{|c|c|c|c|c|c|c|c|c|c|}
\hline & \multicolumn{9}{|c|}{ Strategic Focus } \\
\hline & \multicolumn{3}{|c|}{ Cost } & \multicolumn{3}{|c|}{ Differentiation } & \multicolumn{3}{|c|}{ Mann-Whitney U } \\
\hline & $\mathrm{N}$ & $M$ & SD & $\mathrm{N}$ & $\mathrm{M}$ & SD & $\mathrm{M}-\mathrm{WU}$ & $\mathrm{Z}$ & Sig \\
\hline Organizational Design & 41 & 3.7095 & .36955 & 122 & 3.5795 & .42324 & 1935.000 & -2.168 & .030 \\
\hline Organizational Structure & 41 & 3.6829 & .68699 & 122 & 3.4672 & .93318 & 2244.00 & -.998 & .311 \\
\hline Span of Control & 41 & 4.1037 & .66374 & 122 & 3.4672 & .54730 & 2139.000 & -1.973 & .045 \\
\hline Decision Making & 41 & 3.7866 & .42412 & 122 & 3.7275 & .67954 & 2454.000 & -.182 & .428 \\
\hline Information Management & 41 & 4.0732 & .63798 & 122 & 4.0697 & .79854 & 2405.000 & -.377 & .353 \\
\hline Communication Style & 41 & 4.0720 & .68721 & 122 & 3.4672 & .79445 & 2183.000 & -2.142 & .049 \\
\hline
\end{tabular}

Based on the business level strategic focus, organizational design as a whole and its selected dimensions has been analyzed. Although, the above analysis shows that in terms of organization structure, decision making and information management, cost leadership focused organizations score higher than those of differentiation focused organization, but such differences are not statistically significant. To the dimension of span of control, cost focused organizations score with higher mean than differentiation strategy holders, which appears statistically significant $(0.045<0.05$ at two tailed). Similarly, communication style of the cost strategy focused organizations ahead of differentiation strategy focused organizations with higher mean value, which is statistically significant $(0.049<0.05$ at two tailed).

Apart from those tested dimensions, the overall design of the surveyed organizations was found to vary significantly based on the two selected business level strategies $(0.030<0.05$ at two tailed). It seems from the sample statistics that cost focused organizations have higher mean score than differentiation focused organizations, which implies higher decentralization and both way communication practices in the cost focused firms.

Interestingly, such findings are contrary to the typical strategic management literature, which suggests that differentiation strategy focused firms are supposed to have more decentralization and two-way flow of communication. Based on the KIIs, it was found that size of the organization moderates the relationship here between strategy and design choices. Although strategy is differentiation, among the sample firms in this study, a relatively greater proportion of the owners are actively involved with top level management who typically reluctant to leave the power and autonomy to the lower staff level and management. The socio-cultural orientation might also play a significant role in shaping such notion of top management. 


\section{CONCLUSION}

This research expected to establish at a clear link between organization design and demographic factors across industry type and business operations, which has partially been found. This result will enable the decision makers to consider the socio-cultural effect of design choice. Moreover, this research will create a direct impact on classroom teaching of the related courses through bringing developing country specific examples like Bangladesh around the globe, through relevance, scope and problems. This will also enhance the understanding of organizational culture, performance and behavior as a result of appropriate alignment of design factors (Kesler and Kates, 2010). Moreover, it will broaden the focus proposed by Tsuru and Morishima (2011) that firms' strategic choice of organization design and the way design reflects in product architecture. Relevant case studies can also be developed that focus on the developing country context, which is a major shortage in today's academic world. The greater limitation of this research was to get access to strategic level employees of the organizations, which in some cases limit the implication of findings. The selected service organizations in most of the cases were relatively smaller. Categorizing the organizations in terms of technology and size was also a challenge, particularly for analyzing through using Mann Whitney U, which does not allow more than two groups for statistical test. Examining the combined effect of all selected independent variables could enhance the rigor of research. Also, adding additional variables could help to understand the relative importance of selected independent variables. Although, the snowball sampling method helped to ensure randomized effect, but such method limits the scope of control over the sample respondents. The psychological aspects of designers or top management have also been intentionally discarded in this study, which narrows the implication of the findings. A further research on multi-stage logistic regression modeling based on data collected from strategic level employees and adding more psychological variables within the model will help us to conceptualize the design issues more meticulously and make the design model acceptable to larger stakeholders.

\section{REFERENCES}

Aghion, P., \& Tirole, J. (1997). Formal and Real Authority in Organizations. Journal of Political Economy, 105, 1-29.

Aoki, M. (1986, December). Horizontal vs. Vertical Information Structure of the Firm. American Economic Review, 76, 971-83.

Athey, S., Gans, J., Schaefer, S., \& Stern, S. (1994). The Allocation of Decisions in Organizations. Graduate School of Business Research Paper no. 1322. Stanford, CA: Stanford University, 1994.

Ahmed, S. G. (2002), Public Administration in the Three Decades. In A. M. Chowdhury and Fakrul Alam (eds.), Bangladesh: on the Threshold of the Twenty-First Century. Dhaka, Asiatic Society of Bangladesh, 321-354.

Albers, S., Wohlgezogen, F., \& Zajac, E. J. (2013). Strategic Alliance Structures An Organization Design Perspective. Journal of Management, 22(3), 0149206313488209.

Ben-Ner, A., Kong, F., \& Lluis, S. (2012). Uncertainty, task environment, and organization design: an empirical investigation. Journal of Economic Behavior \& Organization, 82(1), 281-313.

Bhattacharya, A., \&Kundu, A. (2013). Organization Design and Performance: Evidence from India. International Journal of Management \& Marketing Research (IJMMR), 6(2), 93-107

Burns.T., \& StalkBi, G, M. 1961.The management of innovation. London: Tavistock.

Courtright, J. A., Fairhurst, G. T., \&Rogers, L. (1989). Interaction Patterns in Organic and Mechanistic System. Academy Of Management Journal, 32(4), 773-802. doi:10.2307/256568.

Cummings, T. G., \& Worley, C. G. (2009). Organization development and change. Cengage Learning.

De Guerre, D. W., Séguin, D., Pace, A., \& Burke, N. (2013). IDEA: A collaborative organizational design process integrating innovation, design, engagement, and action. Systemic Practice and Action Research, 26(3), 257-279. 
Donaldson, L., \&Joffe, G. (2014). Fit-The Key to Organizational Design. Journal of Organization Design, 3(3), 38-45.

Espinosa, M. D. M. B., \&Lindahl, J. M. M. (2015). Organizational design as a learning enabler: A fuzzyset approach. Journal of Business Research, 69, 1340-1344.

Halonen-Akatwijuka, M. (2004). Organizational design, technology and the boundaries of the firm. University of Bristol, Department of Economics Discussion Paper, (02/540).

Haque, A. S. (1995). The Impact of Colonialism: Thoughts on Politics and Governance in Bangladesh. Paper presented at the Fourth Commonwealth and post-Colonial Studies Conference, Georgia Southern University.

Haque, M. S. (2001), Pride and Performance in the Public service: Three Asian Cases, International Review of Administrative Sciences, 67, 99-115.

Helfat, C. E., \&Karim, S. (2014). Fit between organization design and organizational routines. Journal of Organization Design, 3(2).

Hernaus, T., Aleksić, A., \&Klindzic, M. (2013). Organizing for Competitiveness-Structural and Process Characteristics of Organizational Design. Contemporary Economics, 7(4), 25-40.

Hill, Lucion, B. (1996), Vision. Strategy. Business Processes. Organization Design. Been There? Seen It? Done That? The Government Accountants Journal, 45(6).

Hossain, S., \& Hasan, M. H. (2016). Strategic Human Resource Management (SHRM) Practices in Bangladesh: What Really Makes the Difference? Journal of Strategic Human resource Management, 5(3), 34-42.

Iqbal, S., \& Sharma, R. K. (2012). A Study of Organization Strategies, Structures, Culture Dimensions and Management Control System of Various Retail Formats. Journal of International Business Strategy, 12(1), 39-46

Jahan, F. (2006). Public administration in Bangladesh. Centre for Governance Studies Working Paper Series, 1.

Janićijević, N. (2013). The mutual impact of organizational culture and structure. Economic Annals, 58(198), 35-60.

Kesler, G., \& Kates, A. (2010). Designing strategic organizations: the New Work of executives and hr. People and Strategy, 33(3),14.

Khandwalla, Pradip N. (2002). Effective organizational response by corporates to India's liberalization and globalization. Asia Pacific Journal of Management, 19, 423-448

Larsen, M. M., Manning, S., \& Pedersen, T. (2013). Uncovering the hidden costs of offshoring: The interplay of complexity, organizational design, and experience. Strategic Management Journal, 34(5), 533-552.

Liu, G.J., Shah, R., and Schroeder, R.G., 2006. Linking work design to mass customization: a sociotechnical systems perspective. Decision Sciences, 37(4), 519-545

Meyer, A. (2013). Emerging Assumptions about Organization Design, Knowledge and Action. Journal of Organization Design, 2(3), 16-22. doi:10.7146/jod.2.3.15576

Miles, R. E., Snow, C. C., Meyer, A. D., \& Coleman, H. J. (1978). Organizational strategy, structure, and process. Academy of management review, 3(3), 546-562.

Pearce, J. A., \& David, F. R. (1983). A social network approach to organizational design-performance. Academy of Management Review, 8(3), 436-444.

Randolph, W. (1981). Matching Technology and the Design of Organization Units. California Management Review, 23(4), 39-48.

Roberts, \& Porter, L. W. (Eds.). (n.d.). Handbook of organizational communication, 97-122. Newbury Park, Calif.: Sage.

Thompson, op. cit.: J. Galbraith, Designing Complex Organizations (Reading, MA: Addison-Wesley, 1973

Tolchinsky, P. D., \& Wenzl, L. (2014). High engagement organization design. People and Strategy, $37(1), 34$. 
Tran, Q., \&Tian, Y. (2013). Organizational Structure: Influencing Factors and Impact on a Firm. American Journal of Industrial and Business Management, 3, 229-236.

Trentin, A., Forza, C., \&Perin, E. (2012). Organization design strategies for mass customization: an information-processing-view perspective. International Journal of Production Research, 50(14), 3860-3877. doi:10.1080/00207543.2011.597790

Tsuru, T., \&Morishima, M. (2011). Product Architecture, Organizational Design, and HRM Practices: Comparing Japanese, Korean, and Chinese Firms. Hitotsubashi University, Fukino Project Discussion Paper Series, (27).

Tushman, M., Smith, W. K., Wood, R. C., Westerman, G., \& O'Reilly, C. (2010). Organizational designs and innovation streams. Industrial and Corporate Change, 19(5), 1331-1366.

Weick, K. E. 1987. Theorizing about organizational communication. In F. M. Jablin, L. L. Putnam.K.H.

Williams, T. Craig; Rains, Juliet (2007), Linking Strategy to Structure: The Power of Systematic Organization Design. Organization Development Journal, 25(2).

Zábojník, J. (2002). Centralized and Decentralized Decision Making in Organizations. Journal of Labor Economics, 20(1), 1 